\title{
Use of visual feedback for balance training in hemiparetic Stroke patients
}

\section{Utilização do feedback visual no treinamento do equilíbrio de hemiparéticos por Acidente Vascular Cerebral}

\author{
Fabiane Maria Klitzke dos Santos ${ }^{[a]}$, Franciely Voltolini Mendes ${ }^{[a]}$, Simone Suzuki Woellner ${ }^{[a]}$, \\ Noé Gomes Borges Júnior ${ }^{[\mathrm{b}]}$, Antonio Vinicius Soares ${ }^{[\mathrm{a}] *}$ \\ [a] Faculdade Guilherme Guimbala (FGG), Joinville, SC, Brazil \\ [b] Universidade do Estado de Santa Catarina (UDESC), Florianópolis, SC, Brazil
}

\begin{abstract}
Introduction: Hemiparetic Stroke patients have their daily activities affected by the balance impairment. Techniques that used visual information for training this impairment it seems to be effective. Objective: To analyze the effects of the unstable balance board training and compare two ways of visual feedback: the biomechanical instrumentation and the mirror. Materials and methods: Eight chronic hemiparetic Stroke patients participated in the research, randomized in two groups. The first group (G1) accomplished
\end{abstract}

\footnotetext{
* FMKS: grad., e-mail: fabiklitzke@yahoo.com.br FVM: grad., e-mail: franvoltolini@hotmail.com SSW: grad. (specialist), e-mail: simones.woellner@gmail.com NGBJ: PhD, e-mail: noé.borges@udesc.br AVS: MSc, e-mail: a.vini@ig.com.br
} 
the training with biomechanical instrumentation, and the second group (G2) trained in front of the mirror. Sixteen training sessions were done with feet together, and feet apart. The evaluation instruments that were used before and after the period of training were the Time Up and Go Test (TUGT), Berg Balance Scale (BBS) and the Instrumented Balance Board (IBB), that quantified the functional mobility, the balance and the posture control respectively. Results: The TUGT showed significant results $(\mathrm{p}<0.05)$ favorable to G1. Despite the results of BBS were significant for G2, the intergroup comparison did not reveal statistical significance. Both groups obtained decrease in levels of IBB oscillation, what can indicate a higher stability, however the results did not indicate statistical significance $(p>0.05)$. A strong correlation between all the applied tests was observed in this research. Conclusion: Although the advantages found were different between the groups, in both it could be observed that the training brought benefits, with the transference to the functional mobility.

Keywords: Biofeedback. Postural balance. Stroke.

\section{Resumo}

Introdução: Pacientes hemiparéticos por Acidente Vascular Cerebral (AVC) têm suas atividades diárias afetadas pelo comprometimento do equilíbrio. Técnicas que utilizam informações visuais para o treinamento de adaptação a esse comprometimento parecem ser efetivas. Objetivo: Analisar os efeitos do treinamento do equilíbrio em plataforma instável e comparar duas formas de feedback visual: a instrumentação biomecânica e o espelho. Materiais e método: Participaram da pesquisa oito pacientes hemiparéticos por AVC na fase crônica, randomizados em dois grupos. O primeiro grupo (G1) realizou o treinamento com instrumentação biomecânica e o segundo grupo (G2) realizou esse treinamento em frente ao espelho. Foram 16 sessões, treinando com os pés unidos e com os pés separados. Como instrumentos de avaliação foram utilizados, antes e depois do período de treinamento, o Timed Up and Go Test (TUGT), a Escala de Equilíbrio de Berg (EEB) e a Prancha de Equilíbrio Instrumentada (PEI), que quantificaram a mobilidade funcional, o equilíbrio e o controle postural respectivamente. Resultados: $O$ TUGT revelou resultados significativos $(p<0,05)$ favoráveis ao G1. Apesar de os resultados da EEB terem sido significativos para o G2, a comparação intergrupos não revelou significância estatística. Ambos os grupos obtiveram diminuição nos níveis de oscilação da PEI, o que pode indicar uma maior estabilidade, porém os resultados não indicaram significância estatística $(p>0,05)$. Observou-se forte correlação entre todos os testes realizados nessa pesquisa. Conclusão: Embora as vantagens encontradas tenham sido diferentes entre os grupos, em ambos pôde-se observar que o treinamento trouxe benefícios, com transferência para a mobilidade funcional.

Palavras-chave: Biorretroalimentação. Equilíbrio postural. Acidente Vascular Cerebral.

\section{Introduction}

The mortality rates caused by Stroke in Brazil are the highest in Latin America, so for men (128/100,000 inhabitants), and for women (98.7/100,000 inhabitants), and can be related to social determinants (1), as identified in the study accomplished in Joinville, between 2005 and 2007, where the variation in different districts was observed and its inverse correlation with the level of schooling. In that period 1,734 cases were registered, being 1,034 as the first episode. The incidence rate was of 69.5/100,000 inhabitants (2).
Neuron lesions resulting from the interruption of the blood flux in Stroke, can result in disabilities involving the weakness, sensorial deficits, spasticity, loss of motion selectivity, in addition, aphasia, dysarthria and cognitive impairment (3). An evident symptom is the impairment of the contralateral hemibody distinguished by the hemiparesis. An inability occurs in transfer the weight to the injured side evidencing incapacities and limitations, mainly in relation to the balance and normal mobility $(4,5)$.

The central stimulation is adjusted according to the task and environment. The sensory stimulus are used before, during and after the movement permitting the 
anticipation (feed forward) as preparation for risks that can appear, and the retro feeding (feedback) that permits necessary adjustments to the movement that is being performed, or correction for future movements (3).

The integration of the somatosensory, visual and vestibular systems produces information to the central commands that interpret the messages and return a motor answer allowing the maintenance of the postural control (6). To keep standing, walk and integrate with the environment in a safe and efficient way it is necessary a good posture orientation and a good balance, gotten through suitable postural control. The orientation is the adjustment that allows the positioning and alignment of the body. So the balance keeps the body in the position and suitable orientation during the motor actions (7).

To keep maintenance of the balance in the static posture we generally use movements up to the ankle before little oscillations, hip movements when the support base decreases and becomes more unstable, and the pace strategy avoids fall when it occurs great perturbations (8). Hemiparetic Stroke patients employ very often the pace strategy, and to the maintenance of the support base they use the hip strategy most of the times (9).

Therefore, deficiencies in the integration processes of different concerned systems, resulting from the Stroke, as neural as musculoskeletal, will directly affect the postural control (9), endangering the daily life activities and increasing the risk of falls in these people $(10,11,12)$. In addition the deficit of balance cause more fatigue, disturb attested in a study that compared the spent of energy of patients with and without Stroke during activities on a force plate, the group of patients with Stroke had the energetic demand twice more than the control group (13).

Strategies to the balance rehabilitation have been researched and have been necessary for the recovery of these patients. The use of the unstable board with biofeedback through the biomechanical instrumentation, has already demonstrated benefits in hemiparetic Stroke patients. This kind of training permits the individuals visualizes the dislocation of the body in the anteroposterior, latero-lateral and diagonal directions, and it stimulates the necessary and appropriate adjustments face to the caused oscillation (14).

Visual information can be used to compensate the inappropriate proprioception, and correct the body asymmetry through the reorganization of information, effect observed in the study of Trípoli et al. (4) that used a mirror, and Kerdoncuff et al. (6) that carried out a prospective study and randomized comparing the conventional rehabilitation with the rehabilitation on force plate and visual feedback during three weeks with two sessions a day, obtaining a significant upgrade in the clinic test and in the stabilometry with the use of technic.

Thus, the objective of this research was to analyze the effects of balance training in hemiparetic Stroke patients in unstable board, and compare the use of two ways of visual feedback: the biomechanical instrumentation used by Soares et al. (14), and the training where the patient has as reference the visualized shift by his own image in the mirror.

\section{Materials and methods}

The research had the approval of the Committee of Ethics in Research of Hospital Municipal São José in Joinville, Santa Catarina, Brazil, according to the report number 08011. It is about a randomized clinical trial involving hemiparetic Stroke patients attended in the neurological physiotherapy ambulatory of Faculdade Guilherme Guimbala, in Joinville, Santa Catarina, Brazil.

Eight patients framed in the inclusion criteria which were the presence of hemiparesis by Stroke in the chronic stage, and the capacity of walk independently. The hemiparesis by other pathology determined exclusion criteria, as sensorial aphasia, visual and/or auditory deficits and cognitive deficit. All patients are dexterous.

The patients were randomized into two groups, being the first group (G1) composed by four men affected by the ischemic Stroke, average age of 58 $( \pm 6.8$ ), with time of lesion of 24 months $( \pm 17)$, three of them featuring left hemiparesis and one with right hemiparesis.

In the second group (G2) four male patients participated, being one afflicted by hemorrhagic Stroke and the others by the ischemic type, aging average 53 years old ( \pm 13 ), two of them with left hemiparesis and two with right hemiparesis, with average lesion time of 12 months $( \pm 8.2)$.

In the pre and post tests the patients had the balance, the functional mobility and the posture control evaluated by Berg Balance Scale (BBS), the Timed Up and Go Test (TUGT) and the Instrumented Balance Board (IBB). 
The BBS evaluates the balance through 14 items with scores from 0 to 4 that require keeping positions, or performing tasks of different levels of difficulty. The highest score more independence and safety of the patient. It is a very reliable scale to quantify the evolution after clinic interventions, besides it, it is easy to apply it and it is safe for the patient $(15,16)$.

To monitor the mobility progress, the TUGT is an efficient test, and consists in timing how much time the patient takes to accomplish the following functional activities: standing up from a chair, walking three meters, spinning on his own axis, returning and sit again. A longer time is consistent with the symptomatology of Stroke, whereas the paresis, the spasticity and the asymmetric distribution of the corporal weight, makes the accomplishment of specific functional activities difficult $(17,18)$.

The Instrumented Balance Board (IBB) developed by the Laboratory of Instrumentation (Centro de Ciências da Saúde e do Esporte da Universidade do Estado de Santa Catarina) was used to evaluate and training. It permits to the patient to visualize through the monitor, the oscillations through the sensors disposed in five levels (N1, N2, N3, N4, and N5) located in the bottom side of the board that is unstable. The $\mathrm{N} 1$ is the most stable, the $\mathrm{N} 2$ indicates instability twice higher than N1, and so on (19). Therefore, the values of oscillation seen in each level were multiplied by them, after summed up and divided by five, obtaining a total value. Lower values indicated more stability. The patient remained during the evaluation in orthostatic position for 30 seconds on the board with the arms along the body with the eyes opened, initially with the feet apart (ankles distant 10 centimeters and forefeet free), and followed with the feet together for the same time, keeping 70 centimeters of distance from the eyes to the monitor (14).

The G1 trained the balance through the biomechanics instrumentation (Figure 1A). The system permits the patient accomplish the necessary adjustments to the maintenance of the balance using a visual feedback the oscillation shown on the monitor $(14,19)$. The G2 trained the balance on the same unstable board in front of a mirror (Figure 1B). Both groups trained twice a week, during eight weeks, completing sixteen sessions with the time approximately of thirty minutes.

Each session was accomplished in four series of five minutes each, being two with the feet apart and two with the feet together, with a rest time of two minutes between the series. Both groups were kept in conventional physiotherapy, based in classic kinesiotherapy.

The collected data were tabulated on Microsoft Office Excel $2007^{\mathrm{m}}$, and exported to the Graph Pad Prism $4^{\mathrm{m} m}$ software where the average and standard deviation were determined. To compare the pre and post tests in each group and between them, the Student's $t$ Test was applied for paired samples in significant level of $95 \%(\mathrm{p}<0.05)$. The comparison between the groups was accomplished using the ANOVA (Kruskal-Wallis Test). To determine the correlation between the tests it was used the Pearson Correlation Test $(\mathrm{p}<0.05)$.
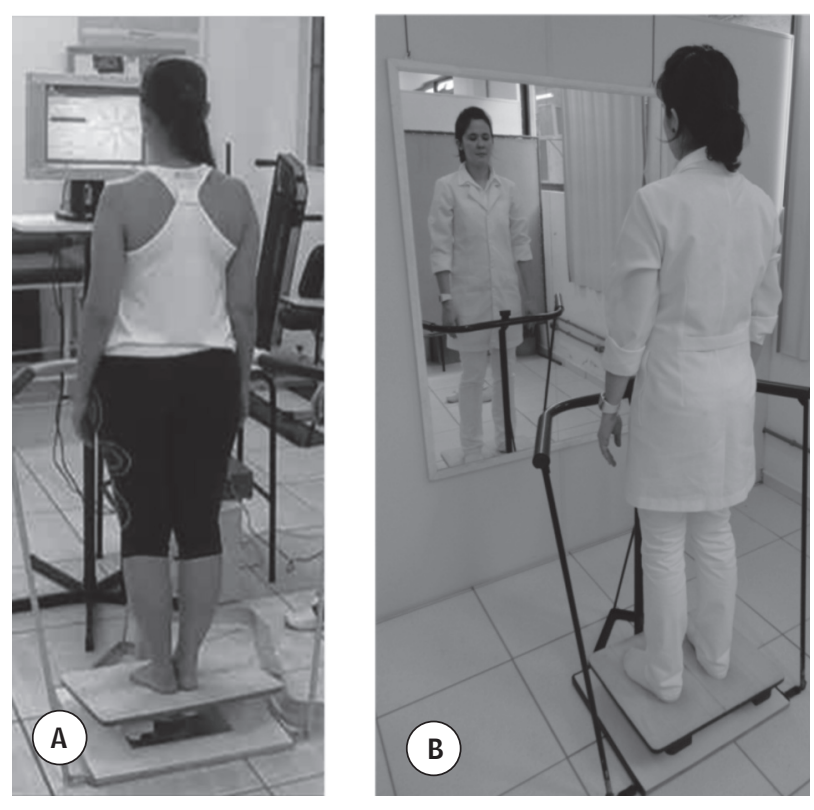

Figure 1 - (A) Simulation of balance training on the Instrumented Balance Board; (B) Simulation of the training in front of the mirror

\section{Results}

Regarded to the individual characteristics, both groups were composed by men and did not differ statistically in terms of age, time of lesion, and results of TUGT pre tests $(\mathrm{p}=0.06)$, scores of BBS $(\mathrm{p}=$ 0.53 ) and levels of oscillation in IBB with feet apart $(p=0.62)$ and feet together $(p=0.95)$.

In relation to the functional mobility evaluated by TUGT both groups had a decrease in average time in the execution of the test, however, only the G1 
obtained significant results. The average time of G1 was of $14.5 \mathrm{~s}( \pm 4.8)$ in the pre test and $11.3 \mathrm{~s}$ $( \pm 3.8)$ in the post test, indicating an improvement of $22.1 \%(\mathrm{p}=0.01)$. The $\mathrm{G} 2$ accomplished the pre test in the average time of $22.8 \mathrm{~s}( \pm 6.1)$, that represents a decrease in time of performance of $9.6 \%(p=0.47)$.

The results of BBS in G1 showed an average of $46.3( \pm 12.5)$ in the pre test, and $52( \pm 4.8)$ in the post test, demonstrating an average increase of 5.7 points $(12.3 \%)$, but, this value was not significant ( $p=0.23)$. In the meantime G2 had an average of $42( \pm 3.2)$ in the pre test and $49.3( \pm 4.3)$ in the post test, average increase of 7.3 points $(17.4 \%)$, indicating statistical significance $(\mathrm{p}=0.02)$.

A strong negative correlation was observed between the results of TUGT and IBB with the obtained value of $r-0,96$ in $G 1$, and $r-0,94$ in G2.

The average oscillation value in IBB can be visualized in the Figures 2 and 3, with feet together

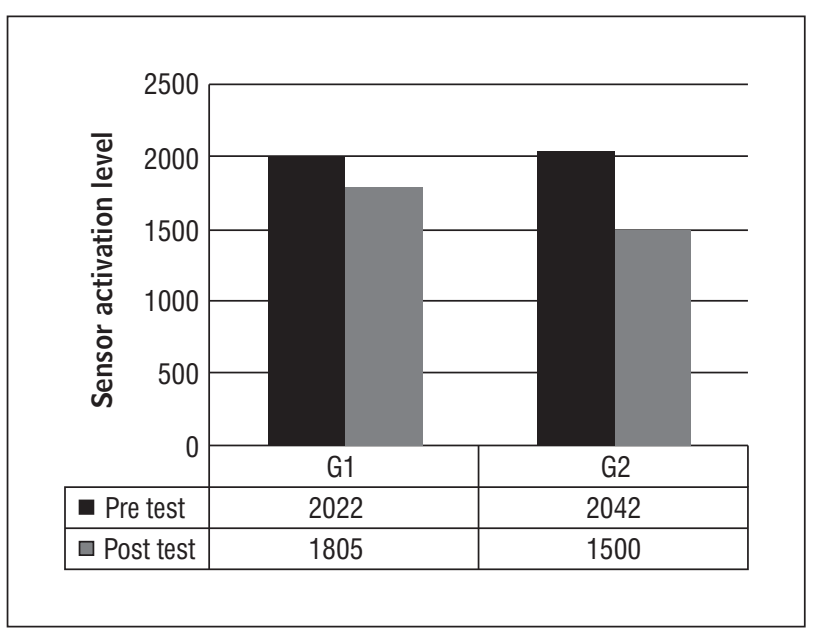

Figure 2 - Comparison between the groups, average values of oscillation on the balance board with feet together, before and after the treatment and apart respectively. Both groups obtained improvement in postural control, although the differences pre and post tests were not significant in both groups. With feet together G1 obtained an improvement of $11 \%(p=0.14)$, and G2 decreased the oscillation in $26.5 \%(p=0.10)$. It is noticeable that G1 reduced the level of oscillation in $6 \%(p=0.47)$ with feet apart and G2 in 19.2\% (p = 0.11) in the same position.

The coefficient $(\mathrm{r}$ ) of correlation test between the results of IBB, TUGT and BBS are represented in Table 1.

When the comparison between the two groups was accomplished the Kruskal-Wallis Test identified a significant statistics difference only in the results of the functional mobility evaluated by TUGT favorable to G1 ( $\mathrm{p}$ <.05). Both the BBS pointing and the level of oscillation of the IBB sensors did not have significant differences ( $p>0.05)$.

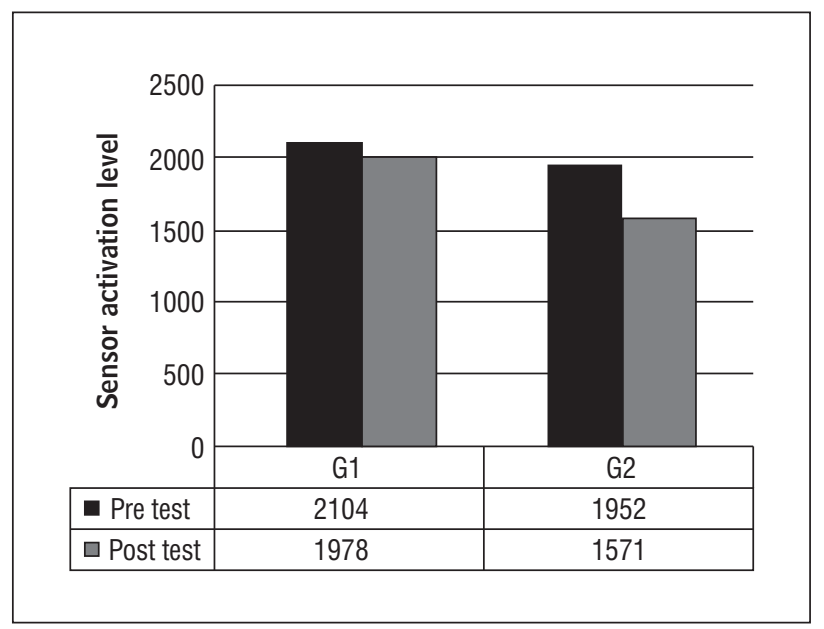

Figure 3 - Comparison between the groups, average values of oscillation on the balance board with feet apart, before and after the treatment

Table 1 - Correlation of IBB with the other tests

\begin{tabular}{|c|c|c|c|c|c|c|}
\hline & \multicolumn{3}{|c|}{ G1 } & \multicolumn{3}{|c|}{ G2 } \\
\hline & IBB ft & TUGT & BBS & IBB ft & TUGT & BBS \\
\hline \multirow[t]{2}{*}{ IBB fa } & $0.95^{\star}$ & $0.87^{\star}$ & $-0.75^{\star}$ & $0.76^{\star}$ & $0.67^{*}$ & $-0.87^{*}$ \\
\hline & IBB fa & TUGT & BBS & IBB fa & TUGT & BBS \\
\hline IBB ft & $0.95^{\star}$ & $0.83^{*}$ & $-0.81^{*}$ & $0.76^{\star}$ & $0.52^{*}$ & $-0.75^{\star}$ \\
\hline
\end{tabular}

Note: IBB fa = Instrumented Balance Board with feet apart; IBB ft = Instrumented Balance Board with feet together; TUGT = Timed Up and Go Test; BBS = Berg Balance Scale. ${ }^{*}$ significant correlation. 


\section{Discussion}

The repercussion related to the central nervous system recurring from the Stroke change the posture reactions endangering significantly the daily activities $(8,9,10,12)$, what makes the training of the postural control a fundamental strategy for the rehabilitation of these patients. Although it does not exist consensus about the best techniques for the training of this function, balance boards associated to the visual feedback are habitually used for this population with different and, so controversial results $(20,21,22,23)$.

The present research had as objective to compare two ways of training the balance on the unstable board with two different kinds of visual feedback, one through the biomedical system and the other using the own image in the mirror. Once the training on unstable boards/surfaces is very common in clinic practice.

Regarding the individuals of the study the sample was constituted by men, age group over 40 , the majority stricken by ischemic stroke, consistent characteristics with the current literature $(1,2,24,25)$. The patients had similar clinic characteristics and they did not differ statistically in age, time of lesion, and results of pre tests, the groups were considered homogenous, permitting the comparison between them.

The decrease in time in the TUGT reflected an improvement of the functional mobility of the patients, with favorable results to G1. In Soares et al. (14) study, the patients trained on IBB the same way as G1 of this study, and it was equally observed after 8 weeks of training a significant decrease in performing time. Therefore, as the TUGT is a good predictor of fall risks it can be emphasized the importance of the balance training for greater safety of the patient in the accomplishment of the functional activities $(11,17)$.

The $\mathrm{G} 2$ trained the balance in front of the mirror, and through the reflected image had the possibility to observe their position and corrected it, being considered an efficient method for the balance and posture training (25). This instrument was also used in the Trípoli et al. study (4) that applied the technique to verify the weight transference to the affected lower limb which was asymmetric on hemiparetic Stroke patients. During the task performance, when the patients were deprived from the visual stimulus the weight unloading became smaller in the injured limb, which was asymmetric, evidenced the dependence of the visual information for the sensorial reorganization.

Srivastava et al. (20), in a prospective study, trained the balance on a force plate with visual feedback and verified an improvement in the rate of BBS and stabilometry, that lead to the functional independence observed through the scores of Barthel Index. In the current research, G2 obtained significant results on BBS scores, however the comparison between the groups do not demonstrate meaningful differences, both evolved in score, that can be the result of a better symmetric weight distribution on the lower limbs (26), since the asymmetry blocks the properly performance of standing from a chair, go up on stairs, among other activities that are evaluated in BBS (27).

This weight unloading more asymmetric was proved in some studies with the use of visual feedback, although in relation to the balance when compared with conventional techniques there were no benefits, despite this, the force plates were stable as the strength ones $(21,23,26)$, and not unstable, like in this study. The unstable plates challenge more the patients, provide more perturbations to the balance and need more dynamic reactions facing the task.

Controversial results are found in studies with patients in a sharper stage of the Stroke. Some researches reveled improvement on scores, although they do not indicate additional benefit in the use of visual feedback, comparing with the rehabilitation without the use of the technique $(28,29)$, however, others obtained advantages using the technique comparing with the conventional physical therapy, with significant results on the score that evaluate the dynamic balance (22).

A comparison between the conventional physiotherapy and the balance training with visual feedback through the Wii Fit in twelve hemiparetic Stroke patients in the chronic stage, demonstrated in both groups, significant improvements on the static and dynamic balance evaluated by BBS. The group that made use of the visual information obtained an advantage in relation to the evaluation on the force plate, where the results were significant in the decrease of anteroposterior oscillation comparing with the conventional technic (5).

To verify the effects on the corporal oscillation Vaillant et al. (30) used a frontal image on a mirror in elderly training. Exactly as they expected, the results indicated a decrease in medio-lateral oscillation, while the anteroposterior oscillation kept unchanged, 
probably by the fact that the reflected image shows more clearly the average lateral oscillations. Possibly the application of IBB would have the advantage to decrease also the anteroposterior oscillations, besides the medio-lateral, regarding that the equipment enables the individual visualize the displacements of his body in all directions (14).

As it was observed, the majority of the studies uses force plates not only for the balance training but, also as an evaluation instrument $(20,17,26,21)$, and reinforcing, the difference of the balance board used in this research is its instability, what demands more concentration to keep the posture regarding the oscillations (14). Soares et al. (14), obtained significant results after the IBB training, where it had a decrease in oscillation of $79.6 \%$ with feet together, and of $119.1 \%$ with feet apart, evidencing potential benefits in its application. Although not significant, in the present research, the use of biomechanical instrumentation and the use of the mirror resulted in average values of minor oscillation, what can indicate a better stability for the patients.

A strong correlation was observed between the IBB and the other tests. The values obtained with feet together correlated positively with the TUGT results and negatively with BBS. It indicates that as less the level of oscillation is, less is also the time to accomplish the TUGT, and higher is the rate in BBS. Therefore, a suitable postural control profit the reactions of balance with positive repercussions over the functional mobility $(10,17,31)$. The strong correlation observed between the IBB and TUGT, was also evidenced in other studies $(10,25,31)$, confirming the fact that individuals with high scores in IBB accomplish the sequence of TUGT with a better performance, observed by the lower run time.

There are benefits with the use of the technic that can be explained regarded to the use of visual information that are fundamental to the maintenance of the balance, as well as supply sensor afferent to the compensatory adjustments face to perturbations (32), being, therefore a relevant help for the individuals rehabilitation with this kind of impairment recurring from the Stroke.

\section{Conclusion}

Disturbs related to the postural control are quite common in hemiparetic Stroke patients, and implies in insecurity, risk of falls and different levels of functional dependence. Therefore, training the postural alignment and the balance reactions are fundamental requirements for the strategies of treatment of this population of patients. Even though there was found different advantages in both groups, in both it could be observed that the training brought benefits along, with transference to the functional mobility.

It is important to remark the necessity to expand the studies about this topic, where it is essential the development of research with a larger number of patients, comparing different techniques, and seek to measure the effects related to the daily life activities, beyond the control and other factors, such as attention and motivation, that can influence decisively the process of rehabilitation.

\section{References}

1. Lotufo PA. Stroke in Brazil: a neglected disease. São Paulo Med J. 2005;123(1):3-4.

2. Cabral NL, Longo A, Moro C, Ferst P, Oliveira FA, Vieira CV, et al. Education level explains differences in stroke incidence among city districts in Joinville, Brazil: a three-year population-based study. Neuroepidemiology. 2011;36(4):258-64

3. Lundy-Ekman L. Neurociência: fundamentos para reabilitação. 3. ed. São Paulo: Elsevier; 2008.

4. Trípoli F, Moreira SR, Oberg TD, Lima NMFV. Tarefas orientadas e biofeedback: efeitos na transferência de peso em hemiparéticos. Acta Fisiatr. 2008;15(4):220-4.

5. Barcala L, Colella F, Araujo MC, Salgado ASI, Oliveira CS. Análise do equilíbrio em pacientes hemiparéticos após o treino com o programa Wii Fit. Fisioter Mov. 2011;24(2):337-43.

6. Kerdoncuff V, Durufle A, Petrilli S, Nicolas B, Robineau $\mathrm{S}$, Lasalle $\mathrm{A}$, et al. Intérêt de la rééducation par biofeedback visuel sur plateforme de stabilométrie dans le prise en charge des troubles posturaux des hémiplégiques vasculaires. Ann Readapt Med Phys. 2004;47(4):169-76.

7. Horak FB. Postural orientation and equilibrium: what do we need to know about neural central of balance to prevent falls. Age Ageing. 2006;35(Suppl 2):ii7-11. 
8. Carvalho RL, Almeida GL. Aspectos sensoriais e cognitivos do controle postural. Rev Neurocienc. 2008; 17(2):156-60.

9. Oliveira CB, Medeiros IR, Frota NA, Greters ME, Conforto $\mathrm{AB}$. Balance control in hemiparetic stroke patients: main tools for evaluation. J Rehabil Res Dev. 2008;45(8):1215-26.

10. Giriko CH, Azevedo RAN, Kuriki HU, Carvalho AC. Capacidade funcional de hemiparéticos crônicos submetidos a um programa de fisioterapia em grupo. Fisioter Pesqui. 2010;17(3):214-9.

11. Belgen B, Beninato M, Sullivan PE, Narielwalla K. The association of balance capacity and falls self-efficacy with history of falling in community-dwelling people with chronic stroke. Arch Phys Med Rehabil. 2006; 87(4):554-61.

12. Weerdesteyn V, Niet M, Duijnhoven HJ, Geurts AC. Falls in individuals with stroke. J Rehabil Res Dev. 2008;45(8):1195-213.

13. Houdijk H, Hoeve N, Nooijen C, Rijntjes D, Tolsma M, Lamoth C. Energy expenditure of stroke patients during postural control tasks. Gait Post. 2010;32(3):321-6.

14. Soares AV, Hochmüller ACOL, Silva P, Fronza D, Woellner SS, Noveletto F. Biorretroalimentação para treinamento do equilíbrio em hemiparéticos por acidente vascular encefálico: estudo preliminar. Fisioter Pesqui. 2009;16(2):132-6.

15. Miyamoto ST, Lombardi Junior I, Berg KO, Ramos LR, Natour J. Brazilian version of the Berg balance scale. Braz J Med Biol Res. 2004;37(9):1411-21.

16. Conradsson M, Lundin-Olsson L, Lindelof N, Littbrand $H$, Malmqvist L, Gustafson Y, et al. Berg balance scale: intrarater test-retest reliability among older people dependent in activities of daily living and living in residential care facilities. Phys Ther. 2007;87(9):1155-63.

17. Ng SS, Hui-Chan CW. The Timed Up \& Go Test: its reliability and association with lower-limb impairments and locomotor capacities in people with chronic stroke. Arch Phys Med Rehabil. 2005;86(8):1641-7

18. Torriani C, Mota EPO, Gomes CS, Batista C, Costa MC, Vieira EM, et al. Avaliação comparativa do equilíbrio dinâmico em diferentes pacientes neurológicos por meio do teste Up and Go. Rev Neurocienc. 2006;14(3):135-9
19. Soares AV, Bertoni A, Borges L, Borges NG. Development and validation of a biomechanical instrumentation to evaluation of the trunk balance. Motor Control. 2007;11(Suppl 1):1-56.

20. Srivastava A, Taly AB, Gupta A, Kumar S, Murali T. Post-stroke balance training: role of force platform with visual feedback technique. J Neurol Sci. 2009;287(1-2):89-93.

21. Geiger AR, Allen JB, O'Keefe J, Hicks RR. Balance and mobility following stroke: effects of physical therapy interventions with and without biofeedback/forceplate training. Phys Ther. 2001;81(4):995-1005.

22. Chen IC, Cheng PT, Chen CL, Chen SC, Chung CY, Yeh TH. Effects of balance training on hemiplegic stroke patients. Chang Gung Med J. 2002;25(9):583-90.

23. Lisinski P, Huber J, Gajewska E, Szlapinski P. The body balance training effect on improvement of motor functions in paretic extremities in patients after stroke. A randomized, single blinded trial. Clin Neurol Neurosurg. 2012;114(1):31-6

24. Goldman L, Ausiello D. Cecil: Tratado de medicina interna. 22. ed. Rio de Janeiro: Elsevier; 2005.

25. O'Sullivan SB. Acidente vascular cerebral. In O'Sullivan SB, Schmitz TJ. Fisioterapia: avaliação e tratamento. 2. ed. São Paulo: Manole; 1993. p. 385-426.

26. Barclay-Goddard R, Stevenson T, Poluha W, Moffat MEK, Taback SP. Force platform feedback for standing balance training after stroke. Stroke. 2005; 36(2):412-3.

27. Costa MCF, Bezerra PP, Oliveira APR. Impacto da hemiparesia na simetria e na transferência de peso: repercussões no desempenho funcional. Rev Neurocienc. 2006;14(2):10-3.

28. Walker C, Brouwer BJ, Culham EG. Use of visual feedback in retraining balance following acute stroke. Phys Ther. 2000;80(9):886-95.

29. Eser F, Yavuzer G, Karakus D, Karaoglan B. The effect of balance training on motor recovery and ambulation after stroke: a randomized controlled Trial. Eur J Phys Rehabil Med. 2008;44(1):19-25.

30. Vaillant J, Vuillerme N, Janvy A, Louis F, Juvin R, Nougier V. Mirror versus stationary cross feedback in controlling the center of foot pressure displacement in quiet standing in elderly subjects. Arch Phys Med Rehabil. 2004;85(12):1962-5. 
31. Thorbahn LDB, Newton RA. Use of the Berg balance test to predict falls in elderly persons. Phys Ther.1996;76(6):576-83.

32. Soares AV. A contribuição visual para o controle postural. Rev Neurocienc. 2010;18(3):370-379.

Received: 07/03/2013

Recebido: 03/07/2013

Approved: 01/22/2015

Aprovado: 22/01/2015 